\title{
De la necesidad a la coyuntura. Evolución de las reflexiones de F. Savater sobre la muerte
}

\author{
From need to situation. Evolution of F. Savater's \\ reflections on death \\ Miguel Grijalba Uche \\ Universidad de Valladolid (España)
}

Recibido: 07.01.2020

Aceptado: 21.01 .2020

\section{RESUMEN}

Ser mortal es saberse mortales. El deseo del ser humano es el deseo de inmortalidad. El pensamiento de Fernando Savater ha evolucionado a lo largo de los ańos en sus variantes filosóficas, políticas y coyunturales. De este modo, su concepto de muerte ha ido sufriendo cambios en esta evolución. Desde una visión libertaria de la muerte entendida como necesidad y a la que se combate con el azar, evoluciona hacia una ética trágica fundada en el querer para alcanzar la inmortalidad, un individualismo y un humanismo centrado en una ética del amor propio hasta culminar, por diferentes razones coyunturales, en una concepción personal de la muerte de la persona amada.

\section{PALABRAS CLAVE}

NECESIDAD; AZAR; TRAGEDIA; INDIVIDUALISMO; AMOR PROPIO

\section{ABSTRACT}

To be mortal is to know mortal. The desire of the human being is the desire for immortality. Fernando Savater's thinking has evolved over the years in his philosophical, political and conjunctural variants. In this way, his concept of death has undergone changes in this evolution. From an ananchirst vision of death understood as necessity and to which one fights with hazard, he evolves towards a tragic ethic to achieve immortality, an individualism and humanism centered on an ethic of self-love until culminating, for different conjunctural reasons, in a personal conception of the death of his wife.

KEY WORDS

NECESSITY; CHANCE; TRAGEDY; INDIVIDUALISM; SELF-LOVE.

Claridades. Revista de filosofía 12/2 (2020), pp. 103-121

ISSN: 1889-6855 ISSN-e: 1989-3787 DL.: PM 1131-2009

Asociación para la promoción de la Filosofía y la Cultura (FICUM) 


\section{INTRODUCCIÓN}

Morir parece algo muY natural ya que nos recuerda la necesidad de desgaste de las cosas y la fragilidad de los seres vivos. Como dice Amelia Valcárcel, nada de lo que vive está preparado para la muerte, por eso los seres humanos la negamos. Por lo tanto, la muerte es un escándalo por ser irrupción en nuestra vida donde la salud y la felicidad han dejado de ser una gracia inalcanzable.

Pero la muerte no es sólo la antiutopía por excelencia (como diría E. Bloch), sino la gran impugnación de nuestras expectativas, deseos, carencias, proyectos y valores que serán cuestionados a partir de ella. Desde la experiencia humana de la negatividad de la vida y del inevitable final de la muerte, surge la búsqueda heideggeriana de un Dios que pueda salvarnos y la pregunta de si esa necesidad tiene una respuesta o si el hombre es sólo una carencia posible.

Ser mortal no significa solamente saber que vamos a morir sino percibir nuestra existencia en el fondo de esa posibilidad, nos dice Savater. Los auténticos vivientes somos los mortales, porque sabemos que dejaremos de vivir y que, en eso precisamente, consiste la vida. De ahí que la muerte sea un motivo de angustia que exige si no una justificación, sí, al menos, una explicación. Y para hacerlo se han inventado los mitos que nos refieren un estado original primigenio donde el hombre era inmortal hasta que, a causa de diferentes circunstancias, Dios o los dioses le castigaron con la muerte. Toda su existencia se convierte entonces en un esfuerzo por recuperar aquel estado primordial.

¿De dónde proviene nuestro afán de inmortalidad? Es difícil aclarar si proviene de un apego afirmativo por la vida, o de la no aceptación de la finitud. Para Nietzsche, este anhelo de inmortalidad sabotea los valores efectivos de la vida y le roba todo su sentido instintivo que es luchar contra la inminencia de la muerte. Por ello, el deseo de inmortalidad no sólo es un deseo humano, sino también humanizador.

Pero, dentro de nuestra realidad, subyace un egoísmo ontológico que nos lleva al escepticismo ante la propia muerte. El mismo ser humano, cristiano o no, no tiene la experiencia de su muerte. Sin embargo, ese escepticismo no exteriorizado, esos temores, con los años y deterioros del cuerpo se convierten en más serios y la fatalidad es inexcusable. Dice Vattimo que sólo muriendo dejamos sitio a otros eventos del ser. La historicidad quiere 
decir mortalidad.

La muerte nos transforma en filósofos ya que el anhelo de inmortalidad es lo que nos hace soñar y nos empuja a la fe. Si, como dice Freud, los sueños son el cumplimiento de nuestros deseos, todo nuestro deseo fundamental es el deseo de inmortalidad, de sobrevivir a la muerte y volver a ver a los seres queridos. En la práctica, la fe en la inmortalidad es la base de la fe en Dios. El hombre cree en Dios porque cree en la inmortalidad. Es decir, lo primero es la inmortalidad y lo segundo la divinidad. Así, el afán de encontrar curación sobrenatural para la muerte siempre es el más sólido fundamento pragmático de la fe, nos refiere L. Feuerbach ${ }^{1}$.

El pensamiento de Fernando Savater ha ido evolucionando en lo personal, en lo filosófico y en lo político a lo largo de su propia existencia. De ahí que podamos definir diferentes períodos en su pensamiento que se reflejarán, igualmente, en diferentes visiones u orientaciones de su idea acerca de la muerte. Desde una visión más metafísica inicial en su período más libertario acabará en un planteamiento más coyuntural en la actualidad. El presente texto pretende esbozar un recorrido por las diferentes etapas del pensamiento savateriano que ha ido modificándose con los años tanto en lo metafísico, como en lo político e, indudablemente, en sus ideas sobre la muerte. Lo que le interesa de la filosofía es la pregunta que incluye las respuestas, tajantes o dubitativas, pero que mantienen abierta la pregunta. Por ejemplo, la pregunta sobre la muerte es una de las preguntas para la cual no hay respuesta al interrogante.

\section{ETAPA ANARQUISTA: NIHILISMO ACTIVO.}

Iniciamos el recorrido por el pensamiento de F. Savater en 1970, época definida por él como nihilista, de un pensamiento negativo con un marcado carácter nietzscheano que lo desarrollará en sus primeros libros. Para la eclosión y desarrollo de su filosofía, fue muy importante la influencia extranjera de predominio francés (Bataille, Deleuze, Foucault, Blanchot, Derrida), como lo recuerda él mismo. Este primer período de pensamiento, a mi entender, abarca desde 1970, y la publicación de su primer libro Nibilismo y acción, y llega hasta las elecciones del 28 de octubre de 1982 dándose dos características intelectuales diferenciadas: la crítica al academicismo continuador del franquismo y la presencia de un esteticismo

1 Cfr. Feuerbach, L. Lecciones sobre la esencia de la religión. Madrid: Tecnos, 2007, p.329. 
ácrata suave como alternativa a una modernidad racionalista, debido a la influencia de García Calvo.

Como explica el propio Savater, la recuperación del pensamiento negativo que tuvo lugar a principios de los años setenta del siglo XX en nuestro país fue un discurso filosófico vinculado a la obra de F. Nietzsche, definido todo él por el rechazo de todo lo que dé sentido a la vida, de todo el orden establecido y del racionalismo. Prácticamente desde este libro, y hasta $L a$ tarea del héroe (1981), Savater sostiene que la tarea de la filosofía es esencialmente negativa ${ }^{2}$. Aquí Savater expondrá su aporía del pensamiento negativo en donde afirma que es posible una razón no sumisa al orden imperante pero que rechaza el inmovilismo escéptico y el desvarío resultante de la negación del sistema hegeliano ${ }^{3}$. Savater se refirió a la acepción "pensamiento negativo» como aquél que desacredita las apologías de lo existente, niega la evidencia del mal y del final positivo ${ }^{4}$. Sólo ve afirmación cuando se rechaza del sentido a la vida. Al fin y al cabo, es un rechazo a todo el sistema hegeliano de reconciliación de la muerte, a la imposibilidad de todo sistema único, a la racionalidad instrumental occidental y al monoteísmo5.

El inicio de este período de su pensamiento vendrá marcado con la publicación de su primer libro titulado Nibilismo y Acción (1970) ${ }^{6}$, gracias a Jesús Aguirre. La represión cultural del franquismo se había encargado de que, en las Facultades de Filosofía, sólo se enseñase una filosofía escolástica. Esta carencia generó un planteamiento crítico y negativo entre los jóvenes filósofos. En ese primer libro, se expone su doctrina del nihilismo en la que se hace cargo de esta idea de muerte. El objetivo de este libro, influido por autores como Cioran, García Calvo, Schopenhauer, Rosset, Celso y Adorno, es hacer saltar lo establecido y defender un trabajo trágico que destruya todos los ídolos (primera parte) y conmine a actuar prescindiendo de todo fundamento otorgador de sentido (segunda parte). Desde Nibilismo y Acción, muestra su concepción libertaria del hombre y su ataque al hegelianismo al considerar Estado como sinónimo de muerte ${ }^{7}$ pro-

2 Savater, F. De los dioses y del mundo. Madrid: Fernando Torres, 1975, p. 25.

3 Savater, F. A decir verdad. Madrid: FCE, 1987, p.20.

4 Savater, F. «Nihilismo», en Quintanilla, M.A. Diccionario de filosofía contemporánea, Salamanca: Sígueme, 1976, p.334.

5 Savater, F. Idea de Nietzsche. Barcelona: Ariel, 1995, p.39.

6 Cfr. Savater, F. Nihilismo y Acción. Madrid: Taurus, 1970.

7 Nogueroles, M. Fernando Savater. Biografía intelectual de un joven filósofo. Madrid: 
poniendo un pensamiento revolucionario que aspire a abolir la necesidad de la muerte y suprima el Estado ${ }^{8}$.

Por tanto, Nihilismo y Acción arremete contra lo que olvida el lado trágico de la vida'. Uno de los pilares fundamentales del nihilismo es la negación de Dios y del orden jerárquico de todos los valores. Savater distingue y analiza entre el ateísmo que niega la existencia de una fuerza sobrenatural y el que niega el derecho de Dios a existir, es decir, niega su esencia. Savater sigue una tercera postura próxima a Cioran al sostener una forma de ateísmo de corte teórico: Dios no es una esperanza sino una amenaza ${ }^{10}$. En el plano religioso, Cioran niega la omnipotencia y bondad de Dios, que otorga la inmortalidad al hombre mediante la salvación ante la muerte y la necesidad. Savater propone, en cambio, actuar desde el carácter finito del hombre el cual niega la necesidad de la muerte y reivindica una ética fundada en el querer. Ésta es la propuesta ética consecuente de Savater, una ética autónoma y ateológica que se pregunta por el qué quiero $\operatorname{ser}^{11}$. Como la doctrina del nihilismo es un fracaso, la única salida que nos queda es la desesperación activa para descubrir que existe una finalidad $\sin f \mathrm{n}^{12}$.

La idea de la muerte es entendida por Savater, en este período, como un sinónimo de la necesidad, como una ley exterior y ajena a nosotros que nos obliga y nos constrińe porque no cesa y con lo que no cabe pacto ninguno ${ }^{13}$. Por lo tanto, la muerte es igual a necesidad ya que lo más necesario es la muerte ${ }^{14}$. Y muerte no significa solamente la eliminación física, sino también la negación hegeliana de la libertad, entendida ésta como encierro en cárceles y manicomios, explotación cara a la productividad, alienación burocrática... Savater se rebela frente a esta explicación al considerarla fruto de una racionalidad instrumental utilitaria y necesaria.

Endymion, 2013, p.134.

8 Ibid., p.108

9 Revilla, A. «El discurso religioso de un ateo practicante: Fernando Savater», en Cabria, JL, Sánchez-Gey, J. Dios en el pensamiento hispano del siglo XX. Salamanca: Sígueme, 2002, 426.

10 Savater, F. Nibilismo y acción. Madrid: Taurus, 1970, p. 46.

11 Savater, F. A decir verdad, o.c., pp.20-21.

12 Savater, F. Nibilismo y acción, o.c., p.85

13 Savater, F. La piedad apasionada. Salamanca: Sígueme, 1977, p.31

14 Savater, F. La filosofía como anhelo de revolución. Madrid: Endymion, 1997, p.45 
Por ello, para combatir a la muerte, Savater utiliza un concepto heredado de Clement Rosset: el azar como el requisito del nihilismo que confirma la condición trágica de la realidad absurda. Si la muerte es la necesidad, sólo se puede atacar desde el azar ya que éste elimina toda culpa, devuelve la inocencia al mundo, supone la ausencia de referencias ${ }^{15}$ y nos muestra el límite de lo pensable ${ }^{16}$ como lo opuesto al sistema y a las explicaciones omnicomprensivas morales ${ }^{17}$. Para Savater, el azar es la garantía del rechazo a toda explicación basada en una voluntad o proyecto originario que hace del hombre un fenómeno más ${ }^{18}$. Con el azar, nos despertamos del sueño teleológico porque todo está tejido de $\operatorname{azar}^{19}$.

El nihilismo significa igualmente la negación de la historia entendida ésta como necesidad, tanto en su versión progresista (cristiana) como secular (marxiana). Frente a esta concepción (un tiempo lineal en la historia), propone Savater un tiempo cíclico que nos acerque al ámbito de lo sagrado, que no tiene nada que ver con lo trascendente, sino con lo que no se puede tocar. Hay un más allá de la ética donde aparece lo sagrado que nos ayuda a superar lo presente y el sufrimiento humano ${ }^{20}$. El término sagrado en Savater nada tiene que ver con la forma habitual de emplear esta palabra porque es lo opuesto al poder, al monoteísmo, al proceso de abstracción, a lo que nos subyace y constituye, en definitiva, a la necesidad y la muerte. La raíz de lo sagrado, que nos causa nuestra condición trágica, es la asimetría entre lo que por esencia nos ignora (Dios) y que nosotros no podemos ignorar $^{21}$. Esta dualidadsagrado/necesidad, que se fundamenta en G. Bataille, trata de una escisión entre el mundo de los deseos frente al orden de las cosas, el cálculo y la necesidad. Lo sagrado es lo que nos asiste en la lucha contra la necesidad y la muerte ${ }^{22}$, y la entrada de Dios socava la importancia de la muerte como definición de lo humano, debido a que la salvación de la muerte la convierte en ilusión ${ }^{23}$.

15 Savater, F. La filosofía tachada,. Madrid: Taurus, 1978, p.128.

16 Ibid., p. 128.

17 Savater, F. La filosofía como anhelo de revolución, o.c., p.63.

18 Savater, F. Diccionario filosófico, o.c., p.273.

19 Nogueroles, M. Fernando Savater. Biografía intelectual de un joven filósofo, o.c., p.95.

20 Savater, F. Invitación a la ética. Barcelona: Anagrama, 1991, pp.126-138.

21 Savater, F. Humanismo impenitente. Barcelona,:Anagrama, 1990, p.198

22 Arias, J. Fernando Savater: el arte de vivir. Barcelona: Planeta, 1999, p.107.

23 Savater, F. Humanismo impenitente, o.c., p.203 
Para Savater, las características de esta muerte son su exterioridad (viene de fuera, la muerte del otro); instrumentalidad (forma parte del juego de la realidad) y materialidad (ligada a leyes físicas) ${ }^{24}$. El ámbito de lo sagrado, por el contrario, se sustrae de la necesidad y lo describe con otras características: intimidad, inutilidad y espiritualidad (entendida no como algo sobrenatural, sino artificial) ${ }^{25}$.

Frente al monoteísmo, al Dios único, el proceso unificador del Todo, a lo homogenizador (en definitiva, la muerte), Savater propone el politeísmo que es lo que admite lo plural, la diferencia, el $\operatorname{azar}^{26}$ y la inmortalidad ${ }^{27}$, siendo el inmoral aquél que permite que el hombre sea dueño de sí mismo y que se abandone al azar del momento ${ }^{28}$. Savater se propone defender una razón plural frente a la razón única o reino mortal de la necesidad. Para Savater, la diferencia fundamental entre el politeísmo (ámbito de lo sagrado) y el monoteísmo (ámbito de lo profano) es que a los primeros se les profesa piedad (como lo improbable, lo adorable) y a los segundos fe (como creencia en lo que no vemos, acatar lo que hay, en concreto, al Estado). Pero el piadoso monoteísta se declara insumiso ante la muerte y provoca que los mitos sean un argumento que narre una vida de una comunidad perfecta de dioses que no alcanzará nunca la muerte, es decir, la necesidad, la razón. La fe monoteísta se acompaña, en definitiva, de una desvalorización de la vida y una glorificación de la muerte porque se ha olvidado a lo sagrado.

Por tanto, la propuesta politeísta es una propuesta contra el poder centralizado del Estado y a favor de una anarquía frente a la necesidad ${ }^{29}$, continuando la influencia del pensamiento de García Calvo. Frente a este planteamiento, cualquier filósofo académico pretende construir un sistema racionalizador del mundo, una verdad absoluta que no deja hueco al azar, a lo individual, a lo sagrado ${ }^{30}$.

En todo este período se refleja lo permanente del pensamiento de Savater: la metáfora politeísta que, más adelante, en sus memorias, recordará

24 Savater, F. La piedad apasionada, o.c., pp.33-34.

25 Ibid., pp.34-36

26 Savater, F. La filosofía como anhelo de revolución, o.c., p.23.

27 Nogueroles, M. Fernando Savater. Biografía intelectual de un joven filósofo, o.c., p.100

28 Ibid., p.114.

29 Savater, F. De los dioses y del mundo, o.c., p.73.

30 Ibid., p.65. 
con poco aprecio. Esta metáfora que encontramos expuesta en sus libros De los dioses y del mundo (1975), Escritos politeístas (1975) o La piedad apasionada (1977) y viene a subrayar la idea de Estado como enemigo, el carácter negativo del pensamiento crítico, la denuncia del dios monoteísta y la sacralización del mundo profano que había separado lo real de lo sagrado, la defensa de la multiplicidad plural de valores que han sido negados por cualquier totalitarismo, la defensa del librepensamiento o el apoyo a la libertad individual autónoma frente a gregarismos de tipo religioso, militar o nacionalista.

En resumen, durante estos años, Savater partiendo desde un escepticismo nihilista llega a la gozosa afirmación del azar como respuesta al sistema y, posteriormente, evoluciona hacia la crítica contra el dios único, entendido como Estado único y centralizador, a la negación en todas las facetas de la vida ${ }^{31}$. Este poder nos coacciona y nos impone la necesidad ${ }^{32}$. La fuerza para librarnos de ese poder surge del ámbito de la intimidad de lo sagrado, una idea libertaria clara que supone la abolición de este Estado ${ }^{33}$. Se trata, según Savater, de un experimento ético creador que nos vivifica al renunciar a la muerte ${ }^{34}$.

Para luchar contra la manipulación que el poder, el Todo, la necesidad imponen al hombre, Savater propone, a continuación y coincidiendo con un giro en su pensamiento, una ética trágica que fundamente lo social. Su pensamiento dejará su combatividad libertaria previa y transitará hacia escritos menos espontáneos y de mayor implicación ética y política. Este proceso culminará con un esbozo de una ética de corte nietzscheano que permitirá al hombre desprenderse de toda moralidad absoluta y universal así como enfrentarse al sistema vigente del Estado, el cual es sinónimo de muerte.

\section{Hacia una ÉTICA TRÁGICA DEL QUERER.}

Tomar conciencia de la muerte, sabernos mortales nos permite apreciar que nuestra vida es resistencia a ella ${ }^{35}$. Frente a los que codician dinero o

31 Savater, F. La filosofía tachada, o.c., p.133.

32 Savater,F. Para la anarquía. Barcelona: Tusquets, 1977, p.19

33 Ibid., p. 12

34 Ibid., p.27

35 Savater, F. Las preguntas de la vida. Barcelona: Ariel, 2007, p. 32. 
nos prometen una vida eterna, Savater presenta un proyecto ético de voluntad que quiere afirmarse frente a la muerte. Es una ética trágica ya que la vida como azar es tragedia, y no hay modo de superar las tensiones que la $\operatorname{posibilitan}^{36}$.

Con esta ética trágica atiende al querer ser sujetos cuya identidad se forja en la apertura a la alteridad. Es decir, necesitamos un reconocimiento por parte de los otros, a los cuales tratamos como fines en sí mismos y no instrumentos. Frente a las éticas renunciativas o normativas (humanas o divinas), Savater propone una ética centrada en afirmar la vida, sin trascendencia pues es inmanentista, autónoma y humanista ${ }^{37}$. Ésta es la tarea del héroe: apostar por la vida y la inmortalidad ${ }^{38}$. Así, Savater con sus dos obras La tarea del héroe (1981) e Invitación a la ética (1982), que marcan el punto de inflexión de su trayectoria intelectual, y emprende la labor de fundamentar una ética autónoma centrada en el querer, ajena de lo trascendente. La propuesta es una ética trágica que se adecue a las necesidades de la sociedad y cuyos principales fundamentos son acción, querer humano y reconocimiento del otro.

Ética significa, para Savater, la negación de la necesidad: lo bueno es bueno porque el hombre lo quiere. El pensamiento ético de Savater tiene su punto de partida en esa visión trágica de lo humano, en donde no hay esperanza ni de salvación ni de reconciliación definitiva porque nada se va a solucionar ${ }^{39}$. De este modo, frente a la ética tradicional se propone una ética trágica que no parte de la distinción entre el bien y el mal (esta distinción será su culminación), que supera el triunfo del bien y, por tanto, será autónoma, sin fundamento trascendente y sin formular normas ni dogmas. Si, para la modernidad, el destino es equivalente a fatalidad y nos conduce a la pasividad, la política y la ética deben sustituir al destino y nos impulsarán a la actividad.

Por tanto, de nuevo la revolución se entiende ahora en el horizonte de la ética, del reconocimiento de la propia libertad, del escepticismo frente a doctrinas salvíficas ante la muerte y la imposibilidad de superar la condición trágica del ser humano. La tarea del héroe, por lo tanto, será la de

36 Savater, F. La tarea del héroe. Madrid: Taurus, 1982, pp.58-66.

37 Savater, F. Ética como amor propio. Madrid: Mondadori, 1988, p.312.

38 Revilla, «El discurso religioso de un ateo practicante: Fernando Savater», o.c., p.428

39 Savater, F. La tarea del héroe, o.c., p.26. 
acometer una revolución ética que trascienda el orden y consiga abolir el poder y la necesidad.

En La tarea del héroe, Savater nos dice que los héroes posibilitan y estimulan nuestra acción ${ }^{40}$, escapan del servilismo y luchan contra todo reduccionismo utilitario e instrumentalista ${ }^{41}$. Este héroe se caracteriza por poseer la virtud, es decir, debe dominar a la adversidad. En concreto, destaca el valor del héroe como virtud, que él lo denomina voluntad de valor ${ }^{42}$, ya que rechaza la necesidad, la instrumentalidad y la muerte. Así, para el hombre vale lo que él quiere ${ }^{43}$. Y lo que quiere es negarse a la necesidad asumiendo su propia ley, como es el caso ejemplar del héroe ${ }^{44}$. Este héroe quiere vencer reconociendo de este modo nuestra independencia sobre la muerte ${ }^{45}$. Por tanto, lo que quiere este héroe es ser, perseverar en el ser y ser reconocido en el otro (ideas en Savater con notable aroma espinosista) ${ }^{46}$. Decir que el hombre es activo es decir que es libre y no sometido ni a la fatalidad, ni a la necesidad pero tampoco al azar (abandonando en este aspecto su postura nihilista y libertaria anterior $)^{47}$. Esta acción supone enfrentarse a las cosas, que tienden a mantenerse en su identidad ${ }^{48}$.

En consecuencia, el ideal ético será implantar y defender la vida contra la necesidad y contra la muerte ${ }^{49}$. Si la aspiración de la ética es revolucionaria, si la política se mueve en el reconocimiento en el otro, esta ética debe oponerse a la violencia y a la desigualdad. Pretende instituir la decisión autónoma de cada cual ${ }^{50}$. Para esta tarea, el héroe contiene, según nuestro autor, un doble ideal: desear la inmortalidad y afirmar la vida ante la muerte irremediable ${ }^{51}$.

40 Ibid., p.113.

41 Savater, F. El contenido de la felicidad. Madrid: Ediciones El País, 1986, p.129.

42 Savater, F. Invitación a la ética. Barcelona: Anagrama, 1982, pp. 55/71.

43 Ibid., p.63.

44 Nogueroles, M. Fernando Savater. Biografía intelectual, o.c., p. 246.

45 Savater, F. La tarea del héroe, o.c., p.114.

46 Savater, F. Invitación a la ética, o.c., p.65.

47 Savater, F. La tarea del héroe, o.c., p.8.

48 Savater, F. Invitación a la ética, o.c., pp.11-14.

49 Ibid., pp.147-148.

50 Savater, F. La tarea del héroe, o.c., p.181.

51 Savater, F. Ética como amor propio. Madrid: Mondadori, 1988, p.312. 
IV. Hacia el individualismo y la Ética del amor propio. Situación ACTUAL ANTE LA MUERTE.

Marta Nogueroles defiende un giro humanista, desde finales de los ochenta, en el pensamiento global de Savater, de contenido laico y hedonista, que pretende hacer que el hombre se desencante de las utopías salvíficas ${ }^{52}$. De este modo, su proyecto ético evolucionará desde la ética trágica anterior hacia una ética del amor propio sin olvidar a la solidaridad colectiva $^{53}$. Pero la perspectiva individual del querer seguirá siendo la del ser, que es lo que significa el amor propio ${ }^{54}$.

El afán del hombre es perseverar en su ser con una duración indefinida. Así Savater ve un proyecto de inmortalidad como sustento de su ética. La virtud, desde el punto de vista de la nueva ética del amor propio, es afirmar la inmortalidad mediante lo que Savater, siguiendo de nuevo a Spinoza, define como alegría ${ }^{55}$. Así, el propósito de la voluntad humana será afirmar y reafirmar el asentamiento de los hombres en la vida que se podrá experimentar como dolor o placer. Para nuestro autor, la búsqueda del placer será el único objetivo de la razón práctica ${ }^{56}$. Savater sustituye la reivindicación de la felicidad por la alegría ya que ésta nos anuda a la vida y al resto de la humanidad. Se trata, por tanto, de un humanismo vitalista donde la alegría crea la virtud como modo de perpetuarse ${ }^{57}$.

$\mathrm{Al}$ asumir la certeza de la muerte, nos había dicho Savater, nos hacemos humanos y sentimos desesperación, miedo, ante la aniquilación, codicia y odio $^{58}$. Sólo queda ahora luchar mediante la experiencia de vida que nos rescata de la muerte sintiendo alegría aunque sea trágica. Una alegría que afirma la vida, la aligera, fomenta la libertad frente a la fatalidad y acepta la vida frente a la muerte. De esta forma, Savater hace patente su herencia de Spinoza y Nietzsche ${ }^{59}$.

52 Savater, F. Humanismo impenitente, o.c., p.13.

53 Ibid., p. 155.

54 Savater, F. Ética del amor propio, o.c., p.36.

55 Nogueroles, M. Fernando Savater, Biografía intelectual, o.c., p.289

56 Savater, F. Ética como amor propio, o.c., pp.136-137.

57 Savater, F. Diccionario filosófico, o.c., p. 47.

58 Savater, F. Despierta y lee. Madrid: Alfaguara, 1998, p. 32

59 Ibid., p.37 
De esa certidumbre nace la idea de que nuestro cuerpo no está garantizado y que es él quien aplaza lo irremediable ${ }^{60}$. La muerte al hacernos mortales nos hace vivientes. Conocer la muerte significa que la vida de cada uno es irrepetible y que todos tememos a la muerte sin remedio ni retorno $^{61}$. La muerte, en consecuencia, es inevitable ${ }^{62}$, necesaria (entendiendo por necesario aquello que no cesa, con lo que no cabe transacción ni pacto alguno), personal e intransferible. Por este motivo, la muerte es individualizadora e igualitaria. Lo que sabemos de la muerte es que es inmanente: desde el primer momento en que empezamos a vivir, ya estamos listos para morir (ya lo dijo Montaigne quien nos afirmó que morimos porque estamos). Por ello, la mejor estrategia de inmortalidad es la lucha por la supervivencia.

La muerte es, para el hombre, un misterio. Savater nos recuerda que algunos, como Epicuro y los materialistas, pensaban que la muerte no es más que una disgregación de los átomos de los que estamos hechos y que, por eso, era nada. En efecto, mientras estamos aquí, la muerte no existe, y cuando ella está, nosotros ya no existimos. Tener miedo a la muerte es tener miedo a la nada ${ }^{63}$. Otros materialistas recurren a la noción de azar para rechazar cualquier tipo de proyecto, voluntad, planificación, como decía Empédocles o Lucrecio ${ }^{64}$. Sin embargo, los no tan materialistas afirman que la muerte es el paso a otro mundo. Así piensan Platón y Séneca, para quienes el día de la muerte es día de nacimiento, dies natalis ${ }^{65}$. Y el prepararse para morir no es otra cosa que pensar la vida mortal que vivimos. Por ello, afirma Savater que casi todo lo que hacemos (tareas y empeńos) lo hacemos para evitar o resistir morir ${ }^{66}$.

60 Savater, F. La vida eterna. Madrid: Ariel, 2007, p.173

61 Savater, F. Diccionario filosófico, o.c., p.207

62 En la Odisea de Homero, Ulises convoca a los espíritus de lo muertos y, entre ellos, acude su amigo Aquiles. Éste le confiesa a Ulises que preferiría ser el último porquerizo en el mundo de los vivos que rey en las orillas de la muerte. Nada deben envidiar los vivos a los muertos.

63 Los ateos se aceptan como mortales y se esfuerzan por acostumbrarse a la nada, nos dice Comte-Sponville. La muerte se lleva todo, pero lo que les importa es la vida terrestre 64 Savater, F. La vida eterna, o.c., p. 237

65 Savater, F. Las preguntas de la vida. Barcelona: Ariel, 1999, p.40.

66 Ante la certidumbre de la muerte, la primera reacción es de angustia y desesperación: miedo, avidez por acumular y odio frente a los que nos disputan los bienes son las características del vivir. Cuando el hombre logra sobreponerse a la desesperación constata 
Por el contrario, Spinoza considera que el hombre en nada piensa menos que en la muerte. El hombre piensa en la vida porque en la muerte no hay nada bueno que pensar. La muerte es negación de vida y, al pensar en ella, nos remite hacia la única alternativa que es intentar comprender la vida ${ }^{67}$. Querer saber y pensar equivale a estar vivo ${ }^{68}$. Nadie parece pensar en su propia muerte, nos dice Savater. No ocurre esto con la muerte de los otros donde, aunque una parte de la relación con ellos se pierda, conservamos otra parte más simbólica. Vattimo, al contrario que Savater, considera que la verdadera muerte escandalosa que debemos soportar no es la nuestra, sino la de nuestros seres más cercanos porque es inconcebible la desaparición radical de una persona para la eternidad. Sin embargo, concluye Savater, debemos aceptar la verdadera raíz de la vida y expulsar la corrupción de la muerte, que es lo que dijo Spinoza con el propósito de vivir racionalmente con perspectiva de inmortalidad.

El problema nos viene cuando tememos que, tras la muerte, no hay nada. Durante mucho tiempo no fuimos, nos dice Savater. Con la muerte iremos al mismo sitio donde estuvimos. En el siglo XVIII Lichtenberg daba la razón a Lucrecio cuando afirmaba que, al nacer, ya hemos resucitado pues provenimos de un estado en el que sabíamos del presente menos de lo que sabemos del futuro. Si la muerte es no ser, la vencimos el día del nacimiento y le hemos robado un cierto tiempo que será un tiempo nuestro, siempre nuestro.

A través de los siglos, ha habido muchas promesas, leyendas, mitos y relatos sobre la muerte que han constituido la base universal de las religiones $^{69}$. En todos los tiempos, la religión ha servido para dar sentido a la muerte. Si no existiese la muerte, nos dice Savater, no habría dioses o los dioses seríamos nosotros mismos ${ }^{70}$. La aceptación de nuestra precariedad es la que nos lleva a soñar con alguien (Dios). Por eso, como decía Feuerbach,

que, en el ahora, está vivo. En una tercera etapa, ya constatada la presencia en la vida, el ser humano exalta de alegría. Una alegría que afirma y asume la vida frente a la muerte. De modo similar describe este proceso Comte-Sponville en su libro El alma del ateísmo. 67 Savater, F. Las preguntas de la vida, o.c., p.43.

68 Ibid., p.47.

69 Todos los dioses son dioses para la muerte, nos dice Savater. Se ocupan del significado de la muerte, reparten premios o castigos, conservan la llave de la vida eterna. Ellos mismos son inmortales.

70 Savater, F. Las preguntas de la vida, o.c., pp.37. 
los dioses son proyecciones de nuestros deseos, de lo inmanente ${ }^{71}$. Pero, en cualquier caso, el ansia de inmortalidad es el motivo esencial de la fe en los dogmas religiosos, al menos para los monoteísmos que prometen una salvación personal. El secreto de la religión es la antropología y la psicología: la noche es la madre de la religión, nos dice L. Feuerbach ${ }^{72}$. Por eso, para Savater, el humanismo supone considerar al hombre como un evento más en la cadena azarosa de lo real sin nada que suponga creación o centro del universo. El peligro, nos dice nuestro autor, es la desmoralización que nos lleva a abandonar el presente y nos entrega a profetas o carismáticos ${ }^{73}$.

Pero el hombre, como ser que anticipa su muerte, es prudente al buscar en el plano espiritual un papel para la muerte como refuerzo de su vida. Aristóteles recomendaba hacernos inmortales viviendo de acuerdo con la parte más excelsa de nosotros mismos, el espíritu. Freud se refiere a los comportamientos que pretenden protegernos contra la inminencia de la muerte utilizando a las creaciones culturales, que aspiran a identificarnos con lo no contingente. La cultura y el arte se presentan como invulnerables a la muerte ya que transcurren por el tiempo sin fallecer ${ }^{74}$. Ortega, en el mismo sentido, decía que el hombre no puede vivir si no hay algo que consiga llenar el espíritu hasta el punto de desear morir por ello. Para Savater, más pragmático, la solución más utilizada culturalmente para alcanzar la inmortalidad simbólica es el amparo del grupo de pertenencia, ya que formamos parte de algo que no muere (aunque como individualidades somos prescindibles): el apego a la familia se ha sustituido colectivamente por la adhesión acrítica a la nación, al Estado o al grupo religioso.

La muerte, dice Savater, nos despoja de nuestra individualidad personal. Morirse es pasar a ser de la mayoría y dejar de ser uno. Como decía Schopenhauer, nada muere con la muerte excepto la individualidad que es sólo presente. Y Unamuno, al igual que Schopenhauer, nos recuerda Savater, defendía un sabernos mortales como especie, pero un no querer morirnos como personas que es lo que nos individualiza ${ }^{75}$. Unamuno re-

71 Feuerbach, F. La esencia de la religión, p. $297 /$ p. 465.

72 Feuerbach, F. Lecciones sobre la esencia de la religión. Madrid: Tecnos, 2007, p.233.

73 Savater, F. Diccionario filosófico, o.c., p.249

74 Savater, F. La vida eterna, o.c., p. 58.

75 Esta idea es lo que nos individualiza a cada uno de nosotros. Unamuno, en El sentimiento trágico de la vida, rechaza con contundencia la muerte y sostuvo que en este mundo o en otro, en caso de haberlo, debemos conservar nuestra personalidad individual. 
chazó la muerte y quería mantenerse con su personalidad. La única vida eterna necesitaría una muerte presente pero aplazada, de ahí el sentimiento trágico de la vida ${ }^{76}$. En opinión de Savater, lo interesante de Unamuno es que desea no morir pero no sabe qué quiere en lugar de morir. Vencer a la muerte no es sinónimo de vivir más tiempo, la única vida eterna compatible unamuniana sería aquella donde existiese la muerte aplazada. Prolongando la vida algo más, como mucho se consigue paliar el afán de vivir por el cumplimiento de objetivos y consecución de placeres ${ }^{77}$. Ferrater Mora planteaba la diferencia entre muerte y continuación indefinida de la vida, un cambio en nuestra calidad de lo vivido ${ }^{78}$, donde siempre habría tiempo para realizar cualquier proyecto, cambiar de opinión, borrar el pasado, etc. En consecuencia, el único sentido de la vida, como afirma Heidegger, es la falta de tiempo existencial de que disponemos, que nos obliga a una administración orientada del mismo. Si hay tiempo, no hay autenticidad ni sentido. Ésta es la perpetua frustración de la vida inmortal, que dejaría de llamarse humana.

Por eso, la muerte preocupa en cuanto que me ocupa de antemano con el temor a perder lo que tengo. Por este motivo, Savater nos dice que la muerte nos hace pensar y nos convierte en filósofos. Si la muerte nos angustia es por algo negativo: por los goces de la vida que perdemos, porque nos deja sin las personas queridas... Cuando la vemos con alivio es por los dolores y afanes de la vida que nos ahorra. En sí misma, la muerte es pura negación, reverso de vida, que de un modo u otro nos remite a esa vida.

Inevitablemente surge un problema teórico, para Savater, porque si nuestra individualidad personal proviene del conocimiento de la muerte y de su rechazo, ¿`cómo podrá Unamuno seguir siendo Unamuno cuando fuese ya inmortal, es decir, cuando ya no hubiese muerte que temer o rechazar?

76 Savater, F. Las preguntas de la vida, o.c., p.38

77 Savater, F. La vida eterna, o.c., p.61.

78 Hablo de existencia y no de vida verdadera. La vida está hecha de cambios, oscilaciones, imprevistos. Por tanto, tampoco las religiones aseguran una vida eterna, sino que sólo prometen una existencia o duración eternas, lo cual no es lo mismo que nuestra vida humana. Savater, junto a Santayana, considera que esa vida perdurable tras la muerte es difícilmente concebible en cuanto que condición misma de vida. Si vivir es la forma de existencia de nuestro cuerpo en el mundo, la vida eterna sin cuerpo ni mundo no puede ser considerada vida. La audacia del cristianismo es la resurrección de los cuerpos, al final de los tiempos, aunque no aclare de qué nos servirá un cuerpo sin necesidad de mecanismos orgánicos ni instinto de conservación. 
Recientemente, se ha producido otro hecho que marca la existencia de Fernando Savater: la muerte de su mujer Sara Torres en marzo de 2015. Savater transita, en este punto y desde ese momento, desde el goce instantáneo, lo efímero, la fidelidad de la tierra y el olvido del cielo, hacia la nostalgia por la pérdida irreparable del ser querido. Esa muerte ha supuesto la ruptura con su yo anterior y define una vida actual sin la alegría que caracterizó a etapas previas. Según sus palabras, ha perdido el combustible existencial que le permitía aguantar, inventar, querer, luchar.

La muerte de la persona amada le ha sumido en un duelo perpetuo que no desea suprimir y que el tiempo no atenúa. Esta muerte y la incomprensión de los que le rodean ante la duración de su duelo le dejan en un aislamiento absoluto. Savater encuentra la esperanza ante esa muerte en el pasado, en lo vivido. La ausencia del otro ocupa todo el futuro y mantenerse en ella es seguir fiel a la persona borrada. Parafraseando a Víctor Hugo, todo el infierno se contendría en una palabra: soledad.

\section{Coda Final}

La muerte es, para Savater, inminente desde el momento en que estamos vivos. Y nos hace realmente humanos, porque nada es más personal que ella, es intransferible ya que es paradigma de la necesidad y, al pensar en ella, somos conscientes de nuestra personal humanidad.

El discurso de Savater es puramente inmanente. Lo que pretende es tratar de dar cuenta de la realidad en su conjunto, dar una respuesta a la pregunta por el sentido de la vida utilizando la búsqueda racional de la verdad. Dentro de un paganismo nietzscheano, acepta que lo sagrado está a la mano del hombre pero reduciendo lo sagrado a una autocomprensión existencial basada en una coherencia entre esta verdad y las coordenadas existenciales de sentido.

Savater rechaza la condición teológica porque su aceptación supondría una negación de la dimensión activa del hombre ${ }^{79}$. Para Savater, la religión ha servido para dar sentido a la muerte. Sin ella, no habría dioses y caeríamos en un ateísmo divinizante ${ }^{80}$. Desde su individualismo voluntarista, marca su descrédito a la muerte por su fondo trágico y pesimista. Sin embargo, no es catastrofista sino vitalista al confiar en la humanidad.

79 Savater, F. La tarea del héroe, o.c., p.75.

80 Savater, F. Las preguntas de la vida, o.c., p.37 
Su noción de la muerte ha evolucionado en el contexto de su pensamiento desde una idea libertaria de muerte como necesidad contra la que se lucha, mediante el azar, pasando por una ética trágica basada en el querer y una posterior ética del amor propio individualista y humanista a, finalmente, una visión más coyuntural de la muerte debido a la muerte de su amada, Sara Torres. Savater es, inicialmente, un pensador libertario que se manifiesta en su exaltación del individuo sin restar su componente social. En un primer periodo del pensamiento de Savater, rechaza las normas universales pero no olvida al otro, ya que el bien de uno mismo no puede estar separado del bien de los demás. Su ética posterior será individualista, inmanente y atea, asentada en el querer.

Para Savater aceptar que el hombre es religioso es la expresión de la certeza irremediable de su aniquilación. De ahí que su opinión sobre la credulidad sea fruto de la cobardía y de la obediencia. Y la conciencia sobre nuestra muerte es la conciencia de nuestra propia individualidad. La muerte, para nuestro autor, es inasimilable. La única manera de enfrentarnos a ella es mediante la otra gran fuerza que nos individualiza, el amor, como bien lo ha demostrado en su último libro La peor parte.

\section{REFERENCIAS BIBLIOGRÁFICAS.}

Arias, J. Fernando Savater: el arte de vivir. Barcelona: Planeta, $1^{\text {a }}$ edición, 1999.

Ávila, R. Fernando Savater. El intelectual y su memoria. Granada: Editorial Universidad de Granada, 1a edición, 2006.

Barnatán, M-R. Fernando Savater contra el Todo. Madrid: Anjana Ediciones, $1^{\text {a }}$ edición, 1984.

Feuerbach, L. Lecciones sobre la esencia de la religión. Madrid, Tecnos, 2007.

Lázaro, J. «La evolución de Savater». El País (26/11/2010).

Martínez Gorriarán, Carlos. «Fernando Savater y su obra: una actualización fundamental de la filosofía». En F. Jiménez Gracia, E. Ujaldón (eds.), Libertad de filosofar. Ética, politica y educación en la obra de Fernando Savater, Barcelona: Ariel, 2007.

Nogueroles, M. Fernando Savater: biografía intelectual de un joven filósofo. Madrid: Endimión, 2013. 
Quintanilla MA. Diccionario de filosofía contemporánea. Salamanca: Sígueme, 1976.

Sauquillo, J. «La vigencia de Nietzsche en el politeísmo valorativo de Fernando Savater», en: Jiménez, F, Ujaldón, E. Libertad de filosofar. Ética, política y educación en la obra de Fernando Savater, Barcelona: Ariel, 2007, pp. 185-228.

Savater, F. Nihilismo y acción. Madrid: Taurus, 1970.

Savater, F. De los dioses y del mundo. Madrid: Fernando Torres editor, 1975.

Savater, F. Escritos politeistas. Madrid: Editorial Nacional, 1975.

Savater, F. La filosofía como anhelo de revolución. Madrid: Ayuso, 1976.

Savater, F. La piedad apasionada. Salamanca: Sígueme, 1977.

Savater, F. Para la anarquía. Barcelona: Tusquets, 1977.

Savater, F. Panfleto contra el Todo. Barcelona: Dopesa, 1978.

Savater, F. La filosofia tachada, precedida de Nibilismo y Acción. Madrid: Taurus, 1978.

Savater, F. La tarea del héroe. Madrid: Taurus, 1982

Savater, F. Invitación a la ética. Barcelona: Anagrama, 1982

Savater, F. El contenido de la felicidad. Madrid: Ediciones El País, 1986.

Savater, F. A decir verdad. Madrid, FCE, 1987.

Savater, F. Ética como amor propio. Madrid: Mondadori, 1988.

Savater, F. Humanismo impenitente. Barcelona: Anagrama, 1990

Savater, F. Diccionario filosófico. Planeta: Barcelona, 1995.

Savater, F. Despierte y lee. Madrid: Alfaguara, 1998.

Savater, F. Las preguntas de la vida. Barcelona: Ariel, 1999.

Savater, F. Diccionario filosófico. Barcelona: Ariel, 2007.

Savater, F. La vida eterna. Barcelona: Ariel, 2007.

Savater, F. La peor parte. Barcelona: Ariel, 2019.

Revilla, A. «El discurso religioso de un ateo practicante: Fernando Savater» En JL Cabria, J. Sánchez-Gey (ed.) Dios en el pensamiento hispano del siglo XX. Salamanca: Sígueme, 2002. Pp. 421-446.

Subirats, H. Fernando Savater. Madrid, Cultura Hispánica, 1993.

Subirats, H. «Laudatio Savater». Araucaria. Revista Iberoamericana de Filosofía, Política y Humanidades. Año 9, no17; 2007.

Vázquez, Francisco. La filosofía española. Herederos y pretendientes. Una lectura sociológica (1963-1990). Madrid: Abada editores, 2009. 
Vázquez, F. Hijos de Dionisos. Sociogénesis de una vanguardia nietzscheana (1968-1985). Madrid: Biblioteca Nueva, 2014.

Miguel Grijalba Uche es doctor en Filosofía por la UNED. Doctor en Medicina por la Universidad de Navarra. Investigador Colaborador del Grupo de Investigación Reconocido "Ciencia y Arte en Filosofía". Facultad de Filosofía. Universidad de Valladolid. Miembro investigador de Hercritia. Facultad de Filosofía. UNED.

\section{Lineas de investigación:}

Filosofía contemporánea con predilección por filosofía francesa Foucault, Deleuze, Sartre. Pensamiento en Heidegger y conexiones Heidegger-Foucault. Filosofía española contemporánea: Trías, Savater.

Publicaciones recientes:

- Miguel Grijalba Uche. 2018. «Hacernos cargo de los débiles. El regreso del pensamiento libertario y comunista como expresión delo debolismo de G. Vattimo», Pensamiento al margen. Número especial, pp.72-88.

- Miguel Grijalba Uche. 2018. «¿Dónde está el error? La epistemología de la verdad en la neurociencia de A. Damasio y la filosofía de R. Descartes», Recerca: revista de pensament $\mathrm{i}$ analisi. 22, pp.69-89.

- Miguel Grijalba Uche; Luis Echarte Alonso. 2017. «Autoengaño y consumismo como elementos coadyuvantes en la construcción de una sociedad transhumanista», Metodología y Didáctica de la Investigación Clinica. 25-1, pp.39-51.

- Miguel Grijalba Uche. 2019. «Reflexiones sobre la antropología de M. Foucault al hilo de la lectura de las palabras y las cosas», en: Chillón, J.M. (Ed.) Hombre y logos. Antropología y comunicación. Madrid: Fragua, pp.93-104.

Dirección electrónica: mgrijalba2003@yahoo.es 
